\title{
Derecho y Realidad
}

Núm. $21 \bullet$ I semestre de 2013

Facultad de Derecho y Ciencias Sociales, UPTC

ISSN: 1692-3936

\section{Enfoque antropológico de la ciencia heráldica (Hacia una renovación conceptual)}

\author{
Anthropological approach of the heraldic science \\ (Towards a conceptual renewal)
}

Florentino Antón Reglero*

\section{Resumen}

La renovación conceptual que la historiografia moderna proporciona a las antiguas ciencias auxiliares de la historia ha permitido a la «ciencia heráldica» dar un salto cualitativo que la separa con claridad del llamado «arte del blasón». Desde este nuevo enfoque, la antropología sociocultural de los siglos de la plenitud medieval europea nos saca del simple diseño de las armerías para acercarnos a lo mental, tanto individual como colectivo, de quienes fueron protagonistas de aquella sociedad.

\section{Palabras clave}

enfoque antropológico de las armerías, ciencia heráldica, arte del blasón, antropología sociocultural, plenitud medieval europea.

\footnotetext{
* Ph. D. en CC. y TT. de la Navegación y de la Construcción Naval, Capitán de la Marina Mercante española; Máster Universitario en Derecho Nobiliario y Premial, Heráldica y Genealogía; Diplomado Superior en Ciencias Historiográficas y en Heráldica Institucional. Académico de Número de la Real Academia de la Mar, del Colegio Heráldico de España y de las Indias y de la Academia Asturiana de Heráldica y Genealogía; exprofesor de Heráldica Institucional de la Cátedra Mosén Diego de Valera de la Agrupación Ateneísta de Estudios Vexilológicos, Heráldicos y Genealógicos, etc.
} 
100

Derecho y Realidad

\begin{abstract}
The conceptual renewal that modern historiography provides to the ancient auxiliary sciences of history has allowed the «heraldic science» to make a qualitative leap that clearly separates it from the so-called «the art of blazon». From this new approach, the sociocultural anthropology of the centuries of the European medieval plenitude, draws us out of the simple design of heraldry and bring us closer to the mental, both individually and as a collective, of who were protagonists in that society.
\end{abstract}

\title{
Key words
}

anthropological approach of the heraldry, heraldic science, the sociocultural anthropology, European medieval plenitude. 


\section{Introducción}

Al surgir a finales del primer tercio del siglo XX la llamada escuela de los Anales $^{1}$, a cuyo pensamiento daría voz la revista homónima creada por sus fundadores, se puso de manifiesto la preocupación de algunos estudiosos por superar la etapa llamada de la historia académica, que desde la perspectiva de nuestro tiempo nos vemos obligados a considerarla "un mero recordatorio de un pasado irremediablemente muerto", como apuntaba Emilio Mitre (1995, p. 15) en su introducción a la primera edición de su Historia de la Edad Media en Occidente.

Pero la renovación conceptual de la historia no fue un hecho aislado y puntual que pueda separarse, ni en aquel tiempo ni ahora, de las trasformaciones sufridas a su vez, y tanto en la base científica de sus contenidos como en el de sus metodologías, del resto de las materias que configuran lo que entendemos, sin duda en un sentido muy general y amplio, como el conjunto de saberes de la humanidad.

Afortunadamente, las diferentes disciplinas que constituyen ese acervo intelectual han dejado de ser compartimentos estancos, facilitándose con ello una labor de interrelación que les ha permitido complementarse, y con ello obtener resultados de mayor nivel y calidad tanto académica como metodológica y científica.

No es por tanto extraño, que a lo largo de ese siglo viéramos a los especialistas de las lenguas o de las humanidades experimentar buscando soluciones matemáticas, por ejemplo, a través de las ciencias, tanto puras como aplicadas, a conceptos encuadrables incluso en el campo de lo abstracto. En definitiva, la matemática es, entre otras cosas, un lenguaje de signos cuya expresión grafica convencional nos permite objetivar tanto las ideas como sus interrelaciones, y de hacerlo de un modo tan perfecto que resultaría muy difícil de alcanzar de otra manera.

Al avanzarse, por tanto, hacia la definición de un nuevo concepto de historia, los especialistas se sintieron necesariamente impulsados a conocer lo mejor posible a los protagonistas de los hechos históricos; pues no se trataba ya tanto de su recopilación y clasificación en el marco de un orden temporal, como de encontrar una justificación que permitiera un mayor y más profundo conocimiento causal de lo acaecido. En realidad, la historia así concebida daba un salto cualitativo al dar protagonismo a las características particulares del núcleo social donde los hechos históricos se habían producido.

1 La llamada Escuela de los Anales (1929) fue una iniciativa de los historiadores franceses Marc Bloch (http://es.wikipedia.org/wiki/Marc_Bloch y Lucien Febvre (http://es.wikipedia.org/wiki/ Lucien_Febvre) interesados por hacer una historia total, en la que se tuviesen en cuenta aspectos de la sociedad como la economía, la sicología y la cultura de la masa social en que se produjeron los hechos históricos objeto de estudio. 
Fue así como se llegó a la llamada "historia de las mentalidades", donde resultó necesario avanzar hacia lo mental colectivo, y de hacerlo de la mano de ciencias tan afines como la antropología sociocultural, buscando para sus investigaciones una epistemología aplicable, que resultara verdaderamente útil al fin histórico, en vez de perderse en aquello que le es más propio a la psicología social (Barros, 2012).

Pero la revisión de los conceptos suele traer consigo también una necesaria actualización o renovación del lenguaje técnico aplicado, y por ello hemos pasado de hablar de historia, y de sus ciencias auxiliares, a hacerlo aglutinándolas todas bajo el común paraguas terminológico de ciencias historiográficas ${ }^{2}$.

No obstante, no nos confundamos, no se ha tratado de un simple maquillaje nominativo. Las ciencias historiográficas han ido alcanzando un alto nivel de desarrollo individual, mientras que, a medida que los métodos de investigación han explorado nuevas vías de trabajo, se consolidaba la calidad científica de sus contenidos disciplinares.

Entendemos por historiografía la ciencia que se dedica al estudio y análisis del modo en que a lo largo del tiempo se ha hecho por el hombre el registro de los acaecimientos históricos. Bajo esta premisa fundamental, que recoge la propia definición, estamos incorporando al conocimiento de los sucesos un nuevo factor humano distinto de aquel al que debemos la generación del hecho en sí, haciéndolo a través de la persona del que lo registra, el historiador, que incorpora su propia percepción e interpretación de lo acaecido a medida que lo analiza, lo evalúa y lo reseña para conocimiento de las generaciones futuras.

Visto así, estamos reconociendo la existencia de un alto grado de subjetivismo en la información que hemos recibido como historia, pues desconocemos cuanto de los sucesos ha sido incorporado a la narración y cuanto puede haber sido intencionadamente excluido de ella; qué intereses personales de carácter anímico,

\footnotetext{
2 Ciencias historiográficas son, por ejemplo: la sigilografía, considerada como la disciplina histórica que tiene por objeto el estudio de los sellos de validación bajo todos sus aspectos y cualquiera que sea su época y significado; la vexilología, tenida por la ciencia que estudia los vexiloides, las banderas, los pendones y los estandartes no sólo como objeto con características determinadas, sino en relación con sus significados y sus usos; la Genealogía, que se ocupa del estudio del los linajes, bien desde su origen como estirpe, bien de ramas específicas, utilizando para ello bases documentales; la arqueología del libro, que supera lo meramente físico que le era propio a la codicología para considerar el libro como un producto cultural capaz de aportar datos socioculturales de su época; la diplomática, ciencia del documento, al que estudia, analiza, critica y explica con el fin de conocer su génesis, su forma, su tradición y su conservación, de modo que pueda mostrar su utilidad tanto jurídica como administrativa, historiográfica o cultural.
} 
ideológico o afectivo movieron al historiador a contarnos los hechos de un modo determinado y no de otro, o qué influyó para que utilizara una determinada metodología en la comprobación previa, si es que la hubo, a la fijación escrita de lo acaecido.

Por ello, hemos de considerar que la historia no es un conocimiento irrefutable. No es una ciencia exacta. Como tampoco, en realidad, lo es ninguna disciplina, pues no podemos olvidar que una de las características de la ciencia es precisamente la de su falibilidad ${ }^{3}$. La de quedar abierta a nuevas posibilidades nacidas de la resolución de nuevas hipótesis, o a la mejor y más amplia comprobación de las consideradas ya plenamente resueltas.

La condición de ciencia del conjunto de disciplinas acogidas al paraguas que les proporciona la historiografía está en realidad en el deseo de acercarse lo más posible a la verdad objetiva, para lo que utiliza recursos y métodos homologables dentro del marco de lo que se considera investigación científica. En este sentido, la fiabilidad y la diversidad de las fuentes consultadas, la corriente ideológica imperante en el medio social en que el acontecimiento tuvo lugar, o la repercusión del hecho en sí, en su proyección hacia el futuro, son factores a tener en cuenta a la hora de valorar el nivel de calidad de los resultados obtenidos.

Entre el conjunto de las ciencias historiográficas al que venimos aludiendo, nos es necesario colocar ahora a la heráldica, motivo fundamental de este trabajo, pues posiblemente sea una de las más antiguas, de las más desarrolladas y de las más cultivadas a lo largo del tiempo; aunque determinados aspectos de su cuna y de su proyección sobre la sociedad occidental de los últimos siglos la hayan hecho caer en el olvido fuera de aquellos círculos que podemos calificar de especializados. Unos ámbitos no ligados específicamente al mundo académico universitario en los últimos tiempos; aunque, afortunadamente, una nueva tendencia parece vislumbrarse ya al ser incorporado su estudio a programas específicos de extensión universitaria.

\section{Las formas heráldicas en su singular proceso de construcción, desarrollo y expansión de marcado carácter sociocultural}

No parece necesario hundirse en un acto de profunda reflexión para comprender que en su nacimiento, y en todo lo que atañe al carácter iconográfico de las expresiones heráldicas, primero fue la partición gráfica del campo del escudo, ese arma defensiva del guerrero cuyo origen se pierde en la noche de los tiempos;

3 La ciencia o el conocimiento científico se caracteriza por ser descriptivo, explicativo, predictivo, metódico, sistemático, contrastable, claro, preciso, objetivo, provisorio o falible y crítico. 
después vendrían las llamadas piezas y las figuras ${ }^{4}$ destinadas a adornarlo con elementos figurativos de naturaleza marcadamente simbólica, en los que el color adquiere una singular importancia; $y$, finalmente, como factor humano que lo impregna todo desde el comienzo, lo espontáneo del hecho original en sí, cuya verdadera percepción nos facilita el comprender la necesidad del enfoque que nos proporciona la antropológica sociocultural a lo largo de todo el proceso de generación, construcción, consolidación, evolución y proyección hasta nuestros días.

Sin duda habrá quien piense, y no sin cierta lógica, que los escudos en el equipo de campaña de los guerreros son una constante a tener en cuenta, por lo que resulta inadecuado hablar de un tiempo de generación de los blasones medievales; pero Fernando del Arco, en sus trabajos sobre la historia de la heráldica, aborda esta cuestión para de algún modo decirnos que las armerías son un producto de la Edad Media en el que, a una tradición totémica anterior, que permanece en la mentalidad de los individuos, se unen las especiales características del pensamiento estético y simbólico del Medioevo (Arco y García, 1999, p. 17-27).

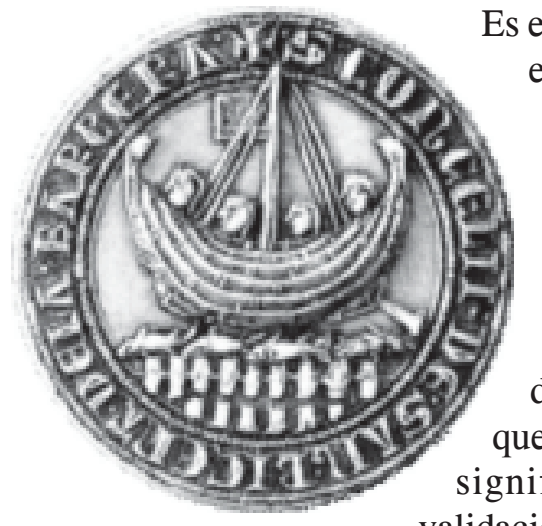

Es esta una afirmación a la que nosotros añadiríamos el gusto por el reconocimiento público del linaje, y por la manifestación, tanto individual como colectiva, de estar en posesión de algún tipo de honor o de autoridad. Algo que ya venía poniéndose de manifiesto con el uso de las señales familiares o institucionales preheráldicas ${ }^{5} \%$ emblemas o figuras clasificadas de este modo por no ajustarse al canon estético que le es propio a los verdaderos blasones, pero significativamente presentes en el sigillum $^{6}$ de validación personal, familiar o colectiva de instituciones religiosas, académicas y municipales \% antes de que los emblemas heráldicos se generalizasen.

$4 \quad$ La heráldica considera piezas a aquellas formas de naturaleza geométrica que se colocan en el campo del escudo para adornarlo, y cuya variedad es muy notable, mientras que llama figuras a aquellas representaciones de entes propios de la naturaleza (figuras naturales), y a aquellos otros derivados tanto de la acción del hombre (figuras artificiales) como de su imaginación (figuras quiméricas).

5 Cuando se inician los usos heráldicos, las llamadas "señales preheráldicas" ya eran utilizadas como emblema por algunos grupos de la sociedad unidos por lazos de parentesco, y por algunas instituciones. Muchas de esas señales evolucionaron para convertirse en armerías, en otros casos se mantuvieron como divisa del tronco familiar, lo que les permitía conservar su libertad gráfica en los diseños, y en otros casos terminaron por desaparecer.

6 Nombre latino con el que son conocidos los sellos de cera utilizados para la validación de todo tipo de cartas y documentos durante el periodo medieval. 
Colocándonos en su origen, en el punto de partida de lo que hoy consideramos las genuinas formas heráldicas, no nos es posible afirmar que los tiempos medievales del origen estuvieran preparados para percibir o pensar en la "heráldica", como concepto, con referencia expresa a cualquiera de esos dos caminos \% el del arte y el de la ciencia ${ }^{7} \%$ que el paso de los siglos, en opinión de Pardo de Guevara (1987, p. 11), daría a la voz un carácter anfibológico que resulta conveniente intentar clarificar ahora, cuando nos hayamos inmersos en una necesaria renovación conceptual de esta disciplina.

En nuestra posición de expertos de hoy no nos está permitido utilizar el término "heráldica" para referirnos solo a las figuras que por su naturaleza le son propias, y que, por otra parte, constituyen el objeto material de estos estudios. Como tampoco debemos utilizar el término con referencia exclusiva a los aspectos formales de esas mismas estructuras. Como es fácil comprender, la idea sobre la que se asientan hoy conceptos como 'arte del blasón' y 'ciencia heráldica' no era parte aún del vocabulario primitivo cuando este fenómeno social surge en pleno siglo XII, bien ligado sin embargo en la actualidad a este particular tipo de emblemas. Es el paso del tiempo el que habría de permitir, a medida que lo espontaneo original se hizo rutina y todo se copia y se recrea siguiendo el orden natural de la imitación, que se fuera desarrollando y fijando como costumbres lo que no había pasado de ser más que tradiciones convertidas en pautas de diseño. Tras ello llegarían a formarse los conceptos, la codificación normativa del buen hacer estético, iniciada en el siglo $\mathrm{XV}$, que llega a su culminación en el XVIII, y la resolución de lo trascendente que encierra todo lo simbólico.

Digamos que el escudo heráldico va más allá de lo estrictamente físico, pues no solo obedece en su construcción a reglas precisas \% arte del blasón \% que se enmarcan dentro de la concepción de la belleza que vive el momento socio-cultural de la sociedad europea del siglo XII, sino que sus formas se llenan de esa capacidad simbólica que les proporciona la personalidad de quién lo configura en su origen, y que lo liga a perpetuidad a un determinado linaje, convirtiéndolo así en un intangible capaz de ser transmitido de generación en generación a los descendientes (MenéndezPidal de Navascués, 1982, p. 11).

Visto de este modo, parece necesario que abordemos ahora la cuestión planteada, confiando en que ello nos permita entender mejor lo que en la actualidad hemos empezado a considerar "ciencia heráldica" : una visión de las armerías mucho más

Debemos entender por "arte del blasón" el conjunto de conocimientos y de reglas de diseño que constituyen el canon de belleza que rige la adecuada composición de los emblemas heráldicos, mientras que hablamos de "ciencia heráldica" cuando consideramos el estudio de estos mismos emblemas desde la perspectiva antropológica de su realidad. 
ligada al alma de los protagonistas (Menéndez-Pidal de Navascués, 1982, p. 11), que al mero estudio o a la práctica de sus soluciones estéticas; pues, al fin y al cabo, podemos decir sin miedo al error, que "las manifestaciones heráldicas, en general, son desde su génesis histórica una respuesta anímica, en forma de expresión gráfica, a unos condicionantes socioculturales propios de una sociedad como la de la plenitud medieval, especialmente dotada para la creación y la percepción simbólica” (Antón, 2010, p. 29).

Indudablemente, el salto cualitativo que representa el paso del enfoque descriptivo: "enumeración y clasificación convencional (ajena a los orígenes) de todas las piezas, muebles, particiones, forros... y todas sus combinaciones posibles, insistiendo [en el uso] de una nomenclatura complicada y casuística" (Menéndez-Pidal de Navascués, 1999, p. 18-20), que es lo que debemos entender por "arte del blasón", a una concepción ligada al ánima de los individuos, a su psiquismo individual y colectivo, \%"ciencia heráldica" \% es de la mayor trascendencia en la renovación conceptual de esta disciplina. Por ello puede decirse que la heráldica es la ciencia que tiene por objeto el análisis, descripción y búsqueda del significado de aquellos símbolos de carácter épico que, como fenómeno social, surgen de forma espontánea entre los siglos XI y XIII, y llegan a nuestros días configurados con arreglo a normas propias y específicas cuyos contenidos reciben en su conjunto el nombre de “arte del blasón” (Antón, 2012, p. 140).

Hemos calificado con anterioridad de época simbólica a la Edad Media europea por ser ese el modo que tuvieron sus gentes de expresar un mundo interior cargado de sensibilidades (Leclercq, 1999, p. 129) impulsadas por la renovadora luz del cristianismo. El problema que se nos plantea a quienes sentimos la necesidad de adentrarnos en la consciencia de esos siglos radica precisamente en comprender su significado más allá de lo puramente alegórico; el cómo llegar a intuir esas sensibilidades del alma del Medioevo desde lo racional de la mentalidad de la sociedad que nos ha educado y en la que vivimos hoy.

Situados, por tanto, ante lo que pudiera considerarse una tridimensional perspectiva desde la que estudiar, analizar y comprender en toda su extensión los contenidos propios de la ciencia heráldica, debiéramos acercarnos hoy a lo que estimamos es el contexto territorial de su origen, para con ello acceder a los mecanismos de su rápida expansión por Europa.

Ciertamente que la base sociocultural, por la que transitaron los grupos humanos donde germinó el conjunto de representaciones que son objeto de estudio por la ciencia heráldica debe ser tenida por la primera dimensión de la perspectiva del trabajo planteado. Sin embargo, el hecho de que su conocimiento pueda ser alcanzado fácilmente, pues ha sido tratado en un número anterior de esta misma revista \% 
el número 12\% (Antón, 2008, p. 53-74) nos invita hoy a fijar la atención del lector en otros aspectos de la sociedad más próximos a su estructura políticoadministrativa, y a sus bases económicas y comerciales, más directamente ligadas al contexto territorial de su origen.

Finalmente, debiéramos asomarnos a los conocimientos que constituyan las bases teóricas con las que se justifica, y en las que se apoya la doble construcción: material y formal de la ciencia heráldica, lo que vendría a constituir una parte esencial de lo que podemos considerar el verdadero núcleo del conocimiento académico que da sentido a esta disciplina. Pero esa es otra cuestión que no podremos, por razones de espacio, abordar hoy aquí de forma específica, aunque de algún modo lo hemos venido haciendo al tratar aspectos puntuales.

\subsection{Contexto territorial de su origen y de su expansión por Europa}

Hasta no hace mucho tiempo, las escuelas de heráldica enseñaban a sus alumnos que el origen de este particular tipo de emblemas, tan propios de la plenitud medieval ${ }^{8}$ tenían su origen en las Cruzadas ${ }^{9}$; sin embargo, no parece constituir esa opinión (Cadenas y Vicent, 1975, p. 12) una verdad irrefutable suficientemente aceptada, pues había, y aún quedan quienes defienden la idea de un origen ligado a los protocolos propios de los torneos y justas ${ }^{10}$ celebrados entre caballeros de la Germania del siglo $\mathrm{X}^{11}$.

Si esto es así, en el primer caso estaríamos hablando de un origen oriental, aunque desde el exclusivo punto de vista del territorio, en el que parece justificarse su génesis ante el necesario reconocimiento físico de los combatientes en el campo de batalla; mientras que en el segundo, centrado en los juegos de instrucción militar de la clase social de los guerreros, lo haríamos con referencia al mismo tipo de protagonistas, pero con la variante de encontrarlos aún en su escenario natural: los territorios propios del Occidente europeo.

8 Se considera perteneciente a la plenitud medieval el período comprendido entre los siglos XII y XIII.

9 Las campañas guerreras llevadas a cabo por ejércitos mixtos de soldados europeos procedentes fundamentalmente de territorios de lo que hoy esFrancia, Inglaterra y Alemania, que son conocidas como Cruzadas por el motivo inicial que las impulsó, es decir, la conquista y protección de los Santos Lugares, se desarrollaron entre los siglos XI y XIII.

10 Torneo: Combate ente caballeros formados en cuadrillas. Justa: Lucha entre dos caballeros a caballo y con lanza. Estos combates podían ser cruentos o incruentos dependiendo del destino fina de los derrotados, pero solían realizarse como entrenamiento para la guerra en periodos de paz.

11 Esta posición, manifestada por algunos heraldistas, no es considerada válida por los historiadores de lo medieval. Resulta demasiado temprana esa época, hasta donde se conoce, para considerar la posibilidad de que ya hubiera escudos heráldicos. 
Podríamos decir también que no han sido estas dos las únicas referencias a un hipotético origen que algunos, con un curioso alarde imaginativo, se han atrevido a ligar incluso a una intervención angélica ${ }^{12}$.

Pero regresando de nuevo al fenómeno psicosocial que nos ocupa, es cierto que el escudo, como arma defensiva de los guerreros, lo hemos dicho ya, parece haber estado presente en todas las culturas. No obstante, no es su percepción como objeto material propio de su equipamiento lo que tiene importancia aquí. No se puede confundir el emblema-armería propiamente dicho con el 'arma objeto', aunque la causa sea el que también en este último caso pueda encontrarse de algún modo adornado, y actuar por ello como emblema de carácter representativo (Piferrer, 1996, p. 8). Sin embargo, por ningún motivo nos está permitido obviar el hecho de que, si bien todas las armerías son emblemas, no por ello todos los emblemas han de ser necesariamente armerías ${ }^{13}$.

Los emblemas heráldicos, cuyo soporte en origen fue el objeto escudo del guerrero, para pasar paulatinamente a figurar diseñado sobre otros materiales a medida que se utiliza como pieza de adorno sometida a la moda, han de cumplir necesariamente la condición de que las marcas, signos, jeroglíficos o empresas, es decir, las piezas y las figuras que lo adornan, se muestren inscritas dentro de un contorno cerrado llamado perfil, y antiguamente boca, que quiere significar con toda claridad aquél escudo protector de los guerreros; poseer valor semiótico o simbólico; tratarse de formas de identificación, propias del Medievo, que evolucionan hacia la condición de marcas de honor trasmisibles a los descendientes; y encontrarse esas marcas sometidas en su diseño a los criterios de estilización y composición heráldica, que incluye el uso correcto de un tipo limitado de esmaltes.

En cuanto al espacio territorial de su origen, el blasón, o escudo de armas, que responde sin duda a lo que autores como Alfonso de Ceballos define como "un hecho social de civilización" (1993, p. 18), se considera hoy ligado en su nacimiento a una amplia faja del espacio europeo comprendida entre los ríos Loira y Rin, que se prolonga por el oeste hacia el sur de Inglaterra (Menéndez-Pidal de Navascués, 1999, p. 21). Es este espacio el que viene a llamarse de la 'heráldica clásica', por ser en el que se observa, en la etapa primitiva que conocemos, un mayor y más intenso grado de perfección y de evolución de las formas.

\footnotetext{
12 La exuberante imaginación de algunos autores de finales del siglo XVIII, en plena era romántica, han ligado el nacimiento de las armerías a mitos bíblicos, haciendo protagonista a San Miguel en sus luchas con Lucifer en los tiempos de la creación del mundo.

13 Emblema: Figura o figuras dispuestas de forma que se toma como representación de algo o de alguien, y cuyo diseño es libre. Emblema heráldico: Figura o figuras ordenadas bajo las leyes heráldicas del blasón que se toman en representación de alguien, sea esta persona física o jurídica.
} 
Por lo demás, no parece que pueda establecerse un origen específico de un punto concreto, pues los emblemas heráldicos se localizan en todo el Occidente europeo sin diferencias cronológicas notables, siendo el fenómeno de la imitación el encargado de su rápida expansión por Europa, haciéndolo de modo tal que, sin dejar de ser fiel a los condicionantes estéticos y simbólicos comunes, adopta aspectos locales que podemos considerar de segundo orden.

Pretender establecer fronteras territoriales en un tiempo como el de la Plenitud Medieval, en el que Europa acaba de iniciar la larga y compleja configuración de sus estados modernos a partir de los múltiples y más o menos extensos señoríos existentes, a los que vemos ligados entre sí por relaciones de tipo vasallático ${ }^{14}$, resulta verdaderamente difícil ${ }^{15}$.

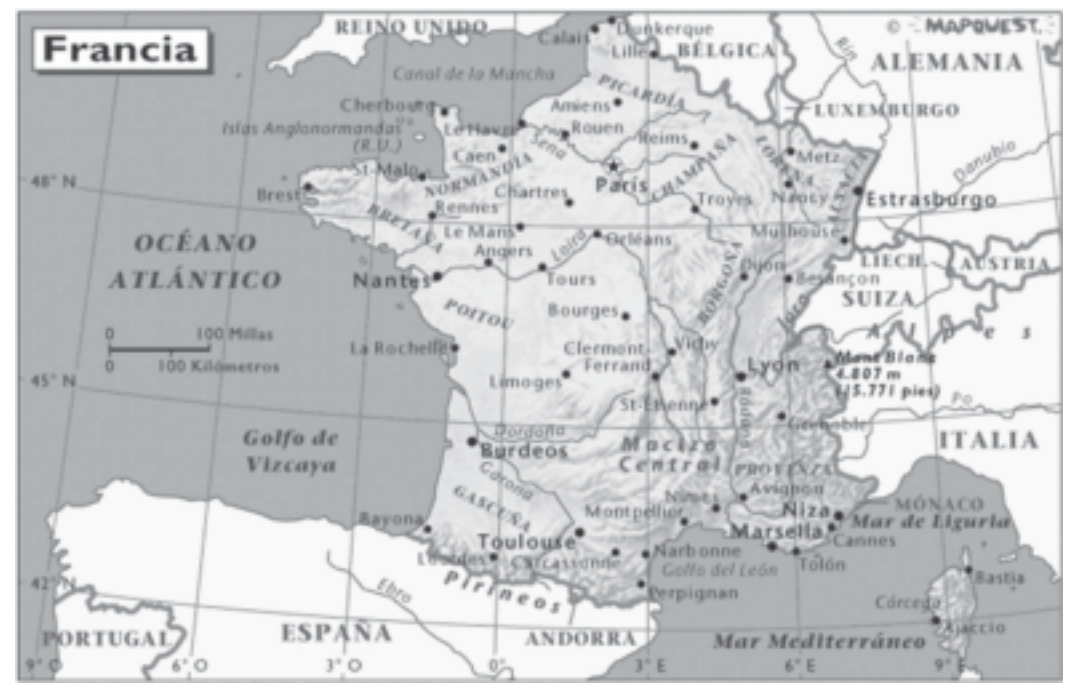

(*) El mapa es sólo orientativo, ya que no todo el espacio entre el Loira y el Rin, además del perteneciente al sur de Inglaterra, aparece representado.

El Loira, que desemboca en el Golfo de Vizcaya, cerca de Nantes, en el límite meridional de la Bretaña francesa, y parece querer dividir el actual territorio francés por su mitad, se convierte en ese tiempo en la frontera sur del espacio territorial que hemos considerado propio del nacimiento de las armerías, mientras que las

14 Se llama vasallaje al vínculo de dependencia y fidelidad que una persona tenía respecto de otra, contraído mediante ceremonias especiales, como el besar la mano el vasallo a quien iba a ser su señor.

15 La estructura del estado feudal se caracteriza por lo limitado del poder de la corona frente al de sus vasallos, que en muchos casos dominansobre territorios más ricos y más extensos que aquellos de los que el rey es señor natural, viéndose obligado a hacer la guerra para defender su primacía o a conceder derechos o privilegios para mantener la lealtad de sus nobles. 
fronteras naturales del norte, en Holanda, y del este, en Alemania, quedan determinadas por la cuenca del Rin, constituyendo así un amplio espacio que salta sobre el Canal de la Mancha para incorporar las tierras del sur de Inglaterra ${ }^{16}$.

Este singular espacio territorial, mosaico de señoríos de mayor o menos peso político, que se asoman al Atlántico en el Canal de la Mancha y en el Mar del Norte, jugará también un importante papel en el comercio de larga distancia por mar; algo que habrá de contribuir notablemente al desarrollo económico y cultural europeo de esos siglos, beneficiando la expansión por Europa de modas entre las que encontramos los usos heráldicos.

Pero no es sólo el comercio de larga distancia o de 'pies polvorientos' el que habrá de servir para impulsar el uso de las armerías por toda Europa. Los matrimonios de conveniencia entre reyes, príncipes y nobles de los distintos señoríos; Las frecuentes contiendas entre ellos por ampliar sus zonas de influencia o de poder; los movimientos de los caballeros que utilizan el ejercicio de las armas para hacer fortuna, trasladándose de un campo de batalla a otro, fundamentalmente en las guerras de cruzada; las cortes itinerantes de los soberanos; los movimientos de estudiantes \% pertenecientes en gran medida a los distintos niveles de la nobleza\% que cambian de universidad siguiendo a los más prestigiosos maestros de su tiempo, y los distintos tipos de movimientos migratorios, se convierten en factores determinantes en la expansión de los usos heráldicos por Europa.

\subsubsection{El espacio geopolítico, económico y cultural europeo en los tiempos propios del nacimiento de las armerías}

La Edad Media europea (Doval, 1996, p. 146), que en sus siete siglos iniciales ve, tras la caída de la Roma imperial en el año 476, como se produce en su tiempo la ocupación de las provincias romanas por las diversas tribus germánicas; que ha asistido al no siempre fácil asentamiento de estos pueblos en los nuevos territorios, en gran medida de población autóctona romanizada; que ha contemplado sus duras luchas intestinas y la formación y consolidación de su estructura social más representativa, el feudalismo ${ }^{17}$, parece querer abordar, en sus siglos centrales,

16 En el espacio indicado existían como territorios predominantes: el ducado de Normandía, el ducado de Bretaña, el ducado de Borgoña, el condado de Champaña, el condado de Blois, el condado de Flandes, el reino de Inglaterra, el ducado de Lorena y territorios del mismo tipo pertenecientes al imperio alemán.

17 Los estudiosos de la sociedad medieval, partiendo de La Ciudad de Dios de San Agustín, la ven conformada por tres estamentos fundamentales: Los oratores (el clero), los bellatores (los guerreros), y los laboratores (el campesinado). Cada uno de ellos con su propia estructura jerárquica y sus regulaciones jurídicas de dependencia. De algún modo, el desarrollo de las ciudades, que se percibe con claridad en el siglo XII, modificó, en la práctica, este planteamiento tan simple al conformarse en ellas un nuevo tipo de sociedad mucho más compleja. 
el tejido de la urdimbre que dará como resultado, a largo plazo, la formación de los principales estados del Occidente cristiano.

Aunque resulta difícil fijar con rotundidad el momento preciso en que se genera una tendencia o da comienzo en el plano comunitario un determinado movimiento de su estructura social, viene considerándose el siglo XII como el del inicio del período llamado del Pleno Medievo, en el que, junto a la progresiva recuperación anímica y económica de la depresión sufrida por su población en torno al milenio, se observa un intento por recobrar, en el sentido romanista del término, la noción de estado (Mitre, 1995, p. 257), con todo lo que ello implica de renovación políticosocial. No es extraño, por tanto, que los siglos centrales del largo periodo medieval sean considerados también como un tiempo de claro crecimiento cultural, al que no son ajenos los distintos movimientos migratorios que en él se producen.

En el plano político, las monarquías desarrolladas del Occidente europeo irán consolidando su posición de dominio territorial, desplazando las concepciones universalistas de emperadores y papas, y ejerciendo, no sin dificultad, un control cada vez más completo de unos estados sometidos a las tensiones propias de la disgregación feudal.

En esta dinámica evolutiva, los esquemas señoriales, que rigen la actividad gubernativa de los estados, comienzan a ser superados a medida que el poder de los príncipes se hace más efectivo. El resultado es la aparición de un funcionariado con cierto nivel de especialización (senescales, condestables, camareros, cancilleres, mayordomos, alféreces, etc. $)^{18}$, que se vinculan al gobierno de instituciones tales como el ejército, la tesorería real, los altos tribunales o los diversos consejos. En definitiva se trata de órganos de nueva planta o reformados de la etapa anterior, la Alta Edad Media, capaces de servir con mayor eficacia a las políticas centrales de control social y territorial en materia de justicia, policía, gobernación o fiscalidad monetaria de las curias regis o cortes reales (Mitre, 1995, p. 257).

La administración territorial, salvando las particularidades propias de cada país, se configura en torno a un espacio perfectamente delimitado, que en Inglaterra se ciñe a los antiguos condados, en Francia a las características propias de las nuevas tierras de dominio real (bailías) y en las coronas castellana, aragonesa y Navarra adopta el nombre de merindades \% divisiones territoriales de nuevo cuño y estructura diferente a las de los condados propios del alto Medievo\%. Puestos al frente de

18 En este tiempo, el poder real centralizado cuenta con funcionarios de corte como el senescal (decano de los servidores de palacio); el condestable (administrador de las caballerizas); el camarero real (administrador de la cámara regia); el mayordomo de palacio (intendente de palacio); el canciller (conservador del sello real); el alférez (general en jefe de las tropas cuando no está presente el rey), etc. 
estas demarcaciones, los sheriffs ingleses, los bailíos franceses y los merinos hispanos gobiernan, mantienen el orden, administran justicia, perciben las tasas reales, e incluso se ven dotados de cierta jurisdicción militar.

Son siglos de avance del derecho, en los que junto a las nuevas teorías sobre el poder, que ponen el acento en la ley para colocarla por encima del monarca, y en los que los órganos legislativos comienzan a tener protagonismo, se generaliza un intento de las monarquías más consolidadas del Occidente europeo por recopilar, en un cuerpo único, la legislación aplicable en sus estados (Mitre, 1995, p. 258-263).

Parece ponerse de manifiesto la necesidad de superar la multiplicidad de las normas legales precedentes, dotadas de una importante raíz de carácter consuetudinario localista, en busca de una mayor uniformidad jurídica. Pronto se verá la necesidad de que expertos se incorporen como peritos a los principales órganos del gobierno y a la administración de los estados. Y es aquí donde el desarrollo de las viejas ciudades y la creación de otras nuevas, hecho que propicia la aparición de la universidad, va a resultará determinante en la construcción de un incipiente funcionariado medio ligado al poder no por el ejercicio de las armas, sino por su conocimiento de las leyes del reino.

En cuanto a los recursos de carácter fiscal con que las finanzas reales cuentan a comienzos del Pleno Medievo, en los reinos hispanos, por ejemplo, se observa un heterogéneo origen que, pese a la eficacia de la nueva administración, se mantiene a lo largo de todo este largo periodo. En primer lugar, los reyes ingresan las rentas procedentes de los territorios de realengo por cuanto son su señor natural. Sin duda las fuentes de ingresos más seguras, pero no las únicas. Los monarcas perciben los derechos de carácter vasallático; las regalías o privilegios específicos de su persona sobre la acuñación de moneda, fundación de mercados, explotación de minas o de salinas; las tasas por expedición de documentos de su cancillería (derechos del sello); las multas, y otros aranceles provenientes de la actividad comercial (Mitre, 1995, p. 262).

Desde el punto de vista económico, el crecimiento medieval experimentado en el siglo XII, fundamentalmente agrario, va a descansar sobre el factor trabajo. Favorecen este crecimiento un largo periodo de expansión demográfica que culmina con el repunte que se observa durante los siglos XII al XIII; el aumento de las superficies cultivables; y los aún vigentes mecanismos de dependencia señorial.

De algún modo, los siglos del Pleno Medievo representan la culminación de un segundo período de expansión comenzado en el norte y centro de Italia en el siglo $\mathrm{X}$, y poco después en el Languedoc, Cataluña y Borgoña, que se extenderá posteriormente hasta alcanzar Germania, Navarra, Aragón y Castilla, para llegar, 
en el siglo XI, a Lorena, Berry, Picardía, e Inglaterra. En el Siglo XII, los Países Bajos y el Norte de Italia constituyen ya la llamada Europa Media donde se celebran las grandes ferias internacionales (Contamine, 2000, p. 126, 129).

Sin embargo, el incremento demográfico (Contamine, 2000, p. 123-124, 127), que ya hemos apuntado como determinante del desarrollo económico, no tendría esa valoración si no hubiera venido acompañado del factor movilidad en sus más diversas manifestaciones (Contamine, 2000, p. 130-131): una migración de corto alcance entre aldeas próximas, o entre la aldea y la ciudad, de la que ya tenemos noticia en el siglo XII; una migración de mayor distancia, que aprovecha vías de especial significado religioso y que es capaz de generar espacios de marcado carácter socio-cultural: ahí están las diversas rutas Jacobeas, en las que son fácilmente reconocibles los antiguos asentamientos de Francos; una migración colonizadora hacia el sur (Reconquista española) y hacia el este, que llega incluso a traspasar el Oder, en el centro de Europa, en busca de buenas tierras de cultivo (Ladero, 1992, p. 18-19; Contamine, 2000, p. 123) y de la que participan fundamentalmente las poblaciones situadas más al norte, en el Sacro Imperio Romano Germánico (Contamine, 2000, p. 130-131); y, por último, un movimiento mucho más diversificado, consecuencia de las guerras de cruzada, destinado fundamentalmente a los asentamientos, más bien costeros, que constituyen los Estados Latinos ubicados en el fondo del saco mediterráneo.

Observamos, por tanto, que al igual que la expansión demográfica tiene una repercusión directa sobre la producción agraria que, en razón de los excedentes, permite el paso de una economía de supervivencia a una economía de mercado, la migración de mano de obra hacia los centros urbanos posibilita la formación del artesanado, y permite el consumo de esos excedentes gracias a los diversos sistemas de intercambio comercial, y al crecimiento demográfico de los núcleos de población.

Es en este marco sociopolítico, económico y comercial, que hemos esbozado por entenderlo común para la Europa más occidental del continente, en el que hemos de situar el nacimiento de la heráldica y su rápida expansión siguiendo el dictado de los condicionantes mentales propios de la imitación que dan como resultado una moda ${ }^{19}$.

Somos conscientes también de la importancia que tuvieron las ciudades en todos estos procesos, incluido el del nacimiento de las universidades, aunque nos hayamos limitado a aludir a su existencia, pero reconocemos que una y otra necesitan ser tratadas con detenimiento, pues su influencia en la sociedad se ha prolongado hasta nuestros días.

19 Moda es el gusto general de la gente, o conjunto de usos y costumbres circunscritos a una época determinada, en cualquier aspecto: vestido, mobiliario, literatura, arte, etc. 


\section{Conclusiones}

Resumiendo lo hasta ahora expuesto, podríamos decir sobre los contenidos del tema tratado:

a) Que hoy es posible considerar que existe una clara diferencia entre lo que debemos entender por "ciencia heráldica" y por "arte del blasón".

b) Que el enfoque que puede dar la antropología sociocultural de cada tiempo a estos estudios es esencial a la hora de comprender mejor las formas y los usos heráldicos desde su origen hasta nuestros días.

c) Que hoy podemos hablar con más seguridad del nacimiento de las manifestaciones heráldicas ligándolas a una zona determinada de Europa.

d) Que ese espacio territorial entre los ríos Lora y Rin, y fundamentalmente en la parte más occidental, fue escenario en el siglo XII de guerras y alianzas de predominio señorial, entre las que caben destacar las libradas por la corona de Francia y el ducado de Normandía, en las que se da la paradoja de que duques, como tales, son vasallos de los reyes franceses, pero , al mismo tiempo, son reyes soberanos de Inglaterra por derecho de conquista de sus antepasados, lo que explicaría la pronta incorporación del sur de la isla a los usos heráldicos.

e) Que la segunda cruzada, o de los nobles, estuvo especialmente ligada a condes y señores de ese mismo territorio, lo que explicaría el que se haya considerado por algún tiempo a estas guerras de conquista de los Santos Lugares como factor determinante en el origen de las formas y de los usos heráldicos.

f) Que las transformaciones económicas, sociales y culturales que sufre Europa en el siglo XII facilitarían la expansión de las formas y de los usos heráldicos en todo el continente europeo.

\section{Lista de Referencias}

Antón, F. (2008). El diseño heráldico desde la perspectiva de la estética medieval. Revista Derecho y Realidad, (12), UPTC, Tunja, Colombia.

Antón, F. (2010, 4-5 de nov.). Influencias marítimas en la heráldica municipal cántabra. III Jornadas de Heráldica y Vexilología Municipales, Madrid, Real Academia Matritense de Heráldica y Genealogía. 
Antón, F. (2012). Heráldica marítima española. Madrid: Real Liga Naval Española.

Arco y García, F. La historia de la heráldica. Revista Iberoamericana de Heráldica, (13), Madrid, Colegio Heráldico de España y de las Indias.

Barros, C. (2012, jun.). Historia de las mentalidades, historia social. Epígrafe: Del sótano al granero. Párrafo 11. Universidad de Santiago de Compostela, España. Recuperado de http://www.h-debate.com/cbarros/spanish/ hm_historia_social.htm

Cadenas y Vicent, V. (1975). Fundamentos de Heráldica. Revista Hidalguía. Madrid, Instituto Salazar y Castro (C.S.I.C.).

Ceballos-Escalera y Gila, A. (1993). Heraldos y reyes de armas en la corte de España. Madrid: Prensa y Ediciones Iberoamericanas.

Contamine, P. (2000). La economía medieval. Madrid: AKAL.

Doval, G. (1996). Nuevo Diccionario de Historia. Madrid: Temas de hoy.

Menéndez-Pidal de Navascués, F. (1982). Heráldica medieval española I (La Casa Real de León y Castilla). Madrid, Instituto Salazar y Castro (C.S.I.C.).

Menéndez-Pidal de Navascués, F. (1999). Leones y Castillos. Madrid: Real Academia de la Historia.

Ladero, M. A. (1992). El mundo de los viajeros medievales. Madrid: Grupo Anaya.

Leclercq, J. (1999). Consideraciones monásticas sobre Cristo en la Edad Media. Bilbao: Desclée Brouwer.

Mitre, E. (1995). Historia de la Edad Media en Occidente. Madrid: Cátedra.

Pardo de Guevara, E. (1987). Manual de heráldica española. Madrid: Aldaba.

Piferrer, F. (1996). Nobiliario de los reinos y señoríos de España, VI, Madrid: Unión Iberoamericana de Municipalistas (facsímil de la ed. de 1860). 